\title{
An Analysis of Chinese Policy Instruments for Climate Change Mitigation
}

\author{
Bo Xu, Qie Sun, Ronald Wennersten and Nils Brandt \\ Department of Industrial Ecology, Royal Institute of Technology (KTH) \\ Teknikringen 34, SE 11428 Stockholm, Sweden
}

Submitted: $20^{\text {th }}$ August 2009 Revised: $10^{\text {th }}$ February 2010 Accepted:12 ${ }^{\text {th }}$ April 2010

\begin{abstract}
Purpose - This paper aims to analyse Chinese policy instruments for climate change mitigation.

Design/methodology/approach - First, the paper reviews Chinese energy consumption per unit of GDP (EC/GDP) in order to determine the overall effects of the combined policy instruments. Second, the different policy instruments are compared in terms of their effects. Third, the actual trends of EC/GDP in two provinces and the instruments adopted by them are analysed on the provincial level.

Findings - The decline in EC/GDP can indirectly reflect the Chinese contribution to mitigation of $\mathrm{CO}_{2}$ emissions since fossil fuels dominate Chinese energy consumption. The national EC/GDP values have shown a declining trend from 2005 to date, indicating that the policy instruments are very important to mitigate climate change as regards reducing EC/GDP. The technological improvement regulations have made the greatest contribution to date to reduce EC/GDP values. The experiences from the Beijing and Shandong province indicate that their final targets in 2010 will be most likely achieved because the different provinces are not only following the national policy instruments but have also developed quite a few new instruments to assist in reaching the these reductions.

Research limitations/implications - There are three limitations regarding Chinese policy instruments analysis. First, the paper does not go far to determine the other factors which can affect EC/GDP apart from policy instruments. Second, some data were lacking and there may be inaccuracies in the existing data that could affect the analysis results. Third, EC/GDP cannot reflect the Chinese contribution to mitigation of $\mathrm{CO}_{2}$ emissions if the composition of Chinese energy consumption changes significantly.

Originality/value - The paper addresses the importance of various policy instruments in reducing EC/GDP. The results can be referenced by Chinese policy makers on both the national and provincial level.

Keywords China, Climatology, Government policy, Energy management, Energy consumption

Paper type Research paper
\end{abstract}

\section{Introduction}

Mitigation of greenhouse gas emissions, mainly by reduction of anthropogenic $\mathrm{CO}_{2}$, is necessary to avoid long-term irreversible climate change (IPCC, 2007). The Chinese National Development and Reform Commission (CNDRC), has pointed out that global warming would increasingly affect China. Chinese $\mathrm{CO}_{2}$ emissions, mainly originating from the combustion of coal, increased from 3.07 billion tonnes in 1994 to 5.07 billion tonnes in 2004 (CNDRC, 2007a). Although China has no obligatory commitment of $\mathrm{CO}_{2}$ mitigation to the world, it makes great efforts to mitigate $\mathrm{CO}_{2}$ emissions. The main approach adopted by the Chinese government comprises policy instruments, including administrative regulations, technological improvement regulations, and economic instruments. The national strategic climate change goal published by the Ministry of Environmental Protection of the People's Republic of China (MEPPRC) is for China to make significant achievements in controlling $\mathrm{CO}_{2}$ emissions by 2010 (MEPPRC, 2008).

The aim of this paper was to analyse existing policy instruments for climate change mitigation in China. This analysis was divided into three stages. First, the actual energy consumption per unit of GDP (EC/GDP) on the national level from 2005 to 2008 was reviewed in order to determine whether the combined policy instruments are being effective in improving overall energy efficiency and mitigating climate change. Second, the different categories of policy instrument adopted at different times were compared in terms of their effects. Third, the actual trends in 
EC/GDP in the provinces of Beijing and Shandong province in the period 2005-2008 and the instruments adopted by these provinces were analysed.

\section{An alternative indicator of reductions in $\mathrm{CO}_{2}$ emissions}

China has achieved rapid economic growth in the past decade and is still striving for growth in the coming decade. Chinese economic growth depends heavily on the consumption of huge amounts of fossil fuel, which represents the major source of $\mathrm{CO}_{2}$ emissions. According to reports from the National Bureau of Statistics of China (NBSC, 2008a), fossil fuels, i.e. coal, crude oil and natural gas, accounted for over $90 \%$ of Chinese total energy consumption from 2005 to 2007 (Table I).

Table I. Composition of Chinese energy consumption 2005-2007

\begin{tabular}{lrrrr}
\hline Year & Coal (\%) & Crude oil (\%) & Natural gas (\%) & Other $(\%)$ \\
\hline 2005 & 69.1 & 21.0 & 2.8 & 7.1 \\
2006 & 69.4 & 20.4 & 3.0 & 7.2 \\
2007 & 69.5 & 19.7 & 3.5 & 7.3 \\
Source: NBSC (2008a) & & & &
\end{tabular}

An absolute reduction quantity in $\mathrm{CO}_{2}$ emissions has not been adopted as the official target measuring national strategies of climate change mitigation. Instead, EC/GDP, which represents the intensity of energy consumption in comparison to economic development, is used by Chinese government to indirectly measure its efforts in mitigating climate change (CNDRC, 2007a). In measuring EC/GDP, energy consumption is calculated from end-use energy consumption of various kinds, including coal, crude oil and their products, natural gas and electricity. The reduction in EC/GDP for a given period indicates that energy was used in a more effective way than previously for economic growth. Since fossil fuels dominate Chinese energy consumption, the decline in EC/GDP can indirectly reflect the Chinese contribution to mitigation of $\mathrm{CO}_{2}$ emissions. As can be seen from Table II, which shows actual EC/GDP in China from 2005 to 2008, the value has been gradually declining over time.

Table II. Actual EC/GDP in China 2005-2008

\begin{tabular}{lcccc}
\hline Year & 2005 & 2006 & 2007 & 2008 \\
\hline $\begin{array}{l}\text { EC/GDP } \\
\text { (tonnes of SCE/10,000 CNY) }\end{array}$ & 1.226 & 1.204 & 1.160 & 1.102
\end{tabular}

Note: SCE = standard coal equivalent. In China, the amounts of different categories of energy are converted into SCE for comparison. The calculation of SCE is made on the basis of standard calorific value of every type of energy, rather than on carbon content.

Source: NBSC (2008b), (2009)

\section{Policy instruments for climate change mitigation in China}

Policy instruments for climate change mitigation in China can be divided into administrative regulations, technological improvement regulations and economic instruments.

\subsection{Administrative regulations}

Administrative regulations adopted by the Chinese national government in recent years mainly consist of: (1) setting national targets, (2) assigning targets to provinces, and (3) establishing a punishment system to ensure compliance.

The national targets refer to annual reductions in EC/GDP. The Chinese national strategic goal regarding climate change is to decrease EC/GDP by $20 \%$ by 2010 compared with the 2005 level 
(MEPPRC, 2008). In order to meet this goal, the overall target reduction was divided into annual targets from 2006 to 2009 which are as references, with an average target decrease rate of $4 \%$ per annum (Table III).

Table III. Chinese EC/GDP targets 2006-2010

\begin{tabular}{lccccc}
\hline Year & 2006 & 2007 & 2008 & 2009 & 2010 \\
\hline EC/GDP & 1.177 & 1.128 & 1.079 & 1.030 & 0.981 \\
(tonnes of SCE/10,000 & & & & & \\
CNY) & & & & \\
Sources: SEPAC (2007) and MEPPRC (2008) & & & & \\
\hline
\end{tabular}

When the national goal for 2010 had been defined, the national government broke down the overall target reduction in EC/GDP and assigned specific targets to every province. The structure of provincial energy supply and consumption was taken into consideration when these targets were assigned. Provinces are allowed to achieve their assigned targets by all legitimate means on the basis of their own situation and many provincial governments have established their own annual targets. Specific provincial annual targets for reductions in EC/GDP from 2006 to 2010 can be found in the Table IV. The provincial targets for 2010 are generally set on the same basis as the national target, i.e. decreasing EC/GDP by $20 \%$ compared with the 2005 level. However, eleven provinces are required to reduce EC/GDP more or less than $20 \%$ by 2010 .

Table IV. Actual EC/GDP values and annual targets for all provinces in China 2005-2010 (Unit: Tonnes of SCE $/ 10,000 \mathrm{CNY})$

\begin{tabular}{|c|c|c|c|c|c|c|c|c|c|c|c|c|}
\hline \multirow[t]{2}{*}{ Year } & \multicolumn{2}{|c|}{2005} & \multicolumn{2}{|c|}{2006} & \multicolumn{2}{|c|}{2007} & \multicolumn{2}{|c|}{2008} & \multicolumn{2}{|c|}{2009} & \multicolumn{2}{|c|}{2010} \\
\hline & $\begin{array}{l}\text { Actual } \\
\text { values }\end{array}$ & Target & $\begin{array}{l}\text { Actual } \\
\text { values }\end{array}$ & Target & $\begin{array}{l}\text { Actual } \\
\text { values }\end{array}$ & Target & $\begin{array}{l}\text { Actual } \\
\text { values }\end{array}$ & Target & $\begin{array}{l}\text { Actual } \\
\text { values }\end{array}$ & Target & $\begin{array}{l}\text { Actual } \\
\text { values }\end{array}$ & Target \\
\hline Beijing & 0.80 & - & 0.760 & 0.77 & 0.714 & 0.72 & 0.662 & 0.68 & - & 0.65 & - & 0.64 \\
\hline Tianjin & 1.11 & - & 1.069 & 1.07 & 1.016 & 1.02 & 0.947 & 0.97 & - & 0.93 & - & 0.89 \\
\hline Shanghai & 0.88 & - & 0.873 & 0.85 & 0.833 & 0.84 & 0.801 & 0.81 & - & 0.77 & - & 0.70 \\
\hline Shandong & 1.28 & - & 1.231 & 1.22 & 1.175 & 1.17 & 1.100 & 1.11 & - & 1.05 & - & 1.00 \\
\hline Zhejiang & 0.90 & - & 0.864 & 0.86 & 0.828 & 0.83 & $0.80^{1}$ & 0.80 & - & 0.76 & - & 0.72 \\
\hline Guangdong & 0.79 & - & 0.771 & 0.76 & 0.747 & 0.75 & 0.715 & 0.73 & - & 0.70 & - & 0.66 \\
\hline Jiangsu & 0.92 & - & 0.891 & 0.88 & 0.853 & 0.86 & 0.803 & 0.82 & - & 0.77 & - & 0.74 \\
\hline Henan & 1.38 & - & 1.340 & 1.32 & 1.285 & 1.27 & 1.219 & 1.22 & - & 1.16 & - & 1.10 \\
\hline Hebei & 1.96 & - & 1.895 & 1.88 & 1.843 & 1.81 & 1.727 & 1.76 & - & 1.65 & - & 1.57 \\
\hline Liaoning & 1.83 & - & 1.775 & 1.76 & 1.704 & 1.70 & 1.617 & 1.64 & - & 1.57 & - & 1.46 \\
\hline Sichuan & 1.53 & - & 1.498 & 1.47 & 1.432 & 1.44 & 1.381 & 1.38 & - & 1.32 & - & 1.22 \\
\hline Hubei & 1.51 & - & 1.462 & 1.45 & 1.403 & 1.40 & 1.314 & 1.35 & - & 1.28 & - & 1.21 \\
\hline Fujian & 0.94 & - & 0.907 & 0.91 & 0.875 & 0.88 & $0.85^{1}$ & 0.85 & - & 0.82 & - & 0.79 \\
\hline Hunan & 1.40 & - & 1.352 & 1.34 & 1.313 & 1.30 & 1.225 & 1.26 & - & 1.20 & - & 1.12 \\
\hline Heilongjiang & 1.46 & - & 1.412 & 1.40 & 1.354 & 1.36 & $1.29^{1}$ & 1.29 & - & 1.23 & - & 1.17 \\
\hline Anhui & 1.21 & - & 1.171 & 1.16 & 1.126 & 1.12 & 1.075 & 1.08 & - & 1.04 & - & 0.97 \\
\hline $\begin{array}{l}\text { Inner } \\
\text { Mongolia }\end{array}$ & 2.48 & - & 2.413 & 2.36 & 2.305 & 2.29 & 2.159 & 2.18 & - & 2.09 & - & 1.86 \\
\hline Shanxi & 2.95 & - & 2.888 & 2.83 & 2.757 & 2.73 & 2.554 & 2.60 & - & 2.46 & - & 2.21 \\
\hline Guangxi & 1.22 & - & 1.191 & 1.17 & 1.152 & 1.15 & 1.106 & 1.11 & - & 1.07 & - & 1.04 \\
\hline Jiangxi & 1.06 & - & 1.023 & 1.01 & 0.982 & 0.98 & 0.93 & 0.94 & - & 0.89 & - & 0.85 \\
\hline Shannxi & 1.48 & - & 1.426 & 1.42 & 1.361 & 1.36 & 1.281 & 1.31 & - & 1.25 & - & 1.18 \\
\hline Jilin & 1.65 & - & 1.591 & 1.55 & 1.520 & 1.53 & 1.444 & 1.46 & - & 1.38 & - & 1.16 \\
\hline Yunnan & 1.73 & - & 1.708 & 1.71 & 1.641 & 1.64 & 1.562 & 1.57 & - & 1.50 & - & 1.44 \\
\hline
\end{tabular}




\begin{tabular}{lllllllllllll}
\hline Chongqing & 1.42 & - & 1.371 & 1.36 & 1.333 & 1.32 & 1.267 & 1.27 & - & 1.21 & - & 1.14 \\
Xinjiang & 2.11 & - & 2.092 & 2.03 & 2.027 & 2.01 & 1.963 & 1.95 & - & 1.85 & - & 1.69 \\
Guizhou & 3.25 & - & 3.188 & 3.12 & 3.062 & 3.06 & 2.875 & 2.94 & - & 2.80 & - & 2.60 \\
Gansu & 2.26 & - & 2.199 & 2.17 & 2.109 & 2.11 & 2.013 & 2.03 & - & 1.91 & - & 1.81 \\
Hainan & 0.92 & - & 0.905 & 0.88 & 0.898 & 0.88 & 0.875 & 0.86 & - & 0.88 & - & 0.81 \\
Ningxia & 4.14 & - & 4.099 & 4.02 & 3.954 & 3.94 & 3.686 & 3.80 & - & 3.60 & - & 3.31 \\
Qinghai & 3.07 & - & 3.121 & 3.01 & 3.063 & 3.06 & 2.935 & 2.94 & - & 2.82 & - & 2.55 \\
Tibet & 1.45 & - & - & - & - & - & - & - & - & - & - & 1.28
\end{tabular}

Note: 1 . There are no exact numbers of actual EC/GDP values in Zhejiang, Fujian and Heilongjiang province in 2008 and the numbers are described as "have achieved the goals which were assigned by the government". Therefore, these numbers are given in italics as that year's annual target in the provinces.

2. The data on EC/GDP annual targets in the provinces 2006-2009 come from Report on the Work of the Government during 2006-2009 in every province. Some of these describe their scheduled administrative goals as "will achieve the goal which were assigned by the government" without exact numbers. These numbers are calculated as a $4 \%$ reduction in the previous year's annual target.

3. The cities of Beijing, Shanghai, Tianjin and Chongqing have the same targets as the other provinces. However, Hong Kong, Macao and Taiwan are not included in Table AI. Data on Tibet are lacking except for the actual EC/GDP value in 2005 and the final scheduled administrative goal for 2010.

Sources: NBSC (2006), (2007), (2008b), (2009) and MEPPRC (2008)

The final component of the administrative regulations comprises a punishment system to guarantee achievement of the targets. In 2007, the Central People's Government of the People's Republic of China (CPGPRC) launched the Energy-Saving and Emission Reduction Program, in which a punishment system to guarantee achievement of the climate change mitigation targets is introduced (CPGPRC, 2007). If a province fails to fulfill its assigned target by 2010, the provincial government will be 'punished'. First, the failure will carry significant weight in evaluations of the provincial government's work and the careers of relevant officials will be affected. Second, the provincial government will have to prepare a compensatory programme within a month, specifically describing how the assigned target could be fulfilled in a given period, and will then have to implement this programme. If this also fails, the officials in charge will be punished according to relevant regulations.

\subsection{Technological improvement regulations}

Regulations promoting energy-saving technology have also been widely adopted in China. This instrument is currently making the most greatest contribution to reducing EC/GDP through improving energy efficiency (Wen, 2009). In September 2006, the national government launched the Outline of China's Energy Saving Technology Policies focusing on the promotion of Chinese energy-saving technology in the long term (CPGPRC, 2006). The technological improvement regulations are mainly implemented in the high energy consumption industries such as thermal power plants, steel, aluminum, cement and ethylene production.

The Chinese governments at national, provincial and local level have developed strict sectorbased baselines for thermal power plants regarding energy efficiency. As a result, a large number of small power plants have been shut down and replaced by the large high-efficiency thermal power plants (CNDRC, 2007b). In 2006, small thermal power plants with a total capacity of 3.14 GW were shut down. In 2007 and 2008, this figure rose to $14.38 \mathrm{GW}$ and $16.69 \mathrm{GW}$ respectively (Wen, 2009). If compared to small power plants with the same capacity, those high-efficiency thermal power plants can save coal up to 32.6 million tonnes every year after 2008 (CNDRC, 2008).

In addition, national and provincial governments are encouraging other industries to replace old facilities with the high efficiency facilities (CPGPRC, 2006). This measure has resulted in a 
distinct decrease in the energy consumption intensity in the past few years. For example, the energy consumption per unit output for steel production in 2007 was reduced by $6.4 \%$ in comparison with the 2005 level, and for aluminium was by $1.3 \%$, for cement was by $5.4 \%$ and for ethylene was by $8.3 \%$ (Wen, 2009).

\subsection{Economic instruments}

In addition to regulations, the Chinese government has also applied a number of economic instruments, of which the major types include categories of tax, flexible pricing systems, subsidies and funding for mitigation actions. An emissions trading mechanism on the provincial level has also been proposed to reduce $\mathrm{CO}_{2}$ emissions in a more cost-effective way.

In 2001, the Chinese government started to use differential tax rates to encourage the development of renewable fuels and to restrict the use of fossil fuels. Since 2001, the value added tax (VAT) on wind power plants has been kept at $8.5 \%$, which is considerably lower than the VAT on coal power plants (17\%). Energy production from biomass has been exempted from VAT, while the VAT on ethanol energy is $13 \%$ and it is exempt from the 5\% consumption tax. In 2005, resource taxes on fossil fuels were raised in order to slow down their exploitation. Meanwhile, the export duties on energy-intensive products were also raised. Since 2007, the VAT on methane production and sales is being paid back to these energy-saving enterprises. In the same year, the export duties on energy-intensive products were raised further and the system was expanded to cover more products. In early 2009, consumption taxes on petrol increased from 0.2 to $1.0 \mathrm{CNY}$ and those on diesel from 0.1 to $0.8 \mathrm{CNY}$. The coal resource tax will rise from $1 \%$ to $3 \%$ in 2009 (MFPRC, 2008).

Electricity tariffs are largely controlled by the Chinese government, and a flexible electricity tariff is an important instrument in adjusting the structure of energy consumption, i.e. an extra tariff has to be paid for excessive energy consumption. In 2004, the flexible electricity tariff approach was initially applied to six energy-intensive industries, producing electrolytic aluminium, ferroalloy, calcium carbide, caustic soda, cement and steel. Since 2005, the use of flexible electricity tariffs has been extended to every industrial sector. In order to control electricity consumption more effectively, the rights to adjust the electricity tariff and to obtain the revenue from this tariff was granted to provincial governments in October 2007.

Since power plants generating electricity from renewable energy usually entail larger investment costs than fossil fuel-based plants, the Chinese government is currently subsidising electricity generated from renewables in order to make them competitive to fossil fuels. A normal way of achieving this is for power plants to be paid a higher price for the same amount of electricity if it is generated from renewable energy.

In 2007, the Chinese national government allocated 1.33 billion CNY as a special fund for reducing emissions of $\mathrm{CO}_{2}$ and other pollutants. These funds can be used to: (1) build monitoring stations to record emissions of $\mathrm{CO}_{2}$ and other pollutants, (2) provide funds for mitigation programmes; (3) expand the working capacity and facilities of environmental departments, and (4) reward provinces, cities and industries that have effectively mitigated emissions. Provinces can also use the funds in accordance with 'Reduction of Major Pollutants, the Central Financial Management of Special Funds Interim Measures' (MFPRC and MEPPRC, 2007). For instance, Shanxi province distributed its funds in four main ways in 2008: paying the interest on loans for mitigation programmes, funding mitigation programmes (no more than $40 \%$ of total investment), building monitoring stations, and rewarding provincial cities and industries for mitigating their emissions. 
In addition to existing economic instruments, it is suggested that a carbon trading system be established on provincial level in order to create more incentives for climate change mitigation and improve its cost-effectiveness (Qian, 2008).

\section{Analysis of policy instruments}

In the following, the three categories of policy instrument described above are analysed on national and provincial level.

\subsection{Policy instruments on national level}

There are some other factors affecting EC/GDP apart from policy instruments such as industrial structure, energy market and technology innovation. However, policy instruments can also be used to adjust these factors, which in turn will impact on Chinese EC/GDP.

Table V shows the annual EC/GDP change rates in China from 2003 to 2008. In comparison, the national EC/GDP increased by 4.9\%, 5.5\% and 0.2\% in 2003, 2004 and 2005 respectively, and it just starts to decrease in 2006. Therefore, policy instruments, especially which are adopted after 2005 in China are very important to reduce EC/GDP and make a great contribution to climate change mitigation.

Table V. Annual EC/GDP change rates in China 2003-2008

\begin{tabular}{|c|c|c|c|c|c|c|}
\hline Year & 2003 & 2004 & 2005 & 2006 & 2007 & 2008 \\
\hline $\begin{array}{l}\text { Annual } \\
\text { EC/GDP }\end{array}$ & $+4.9 \%$ & $+5.5 \%$ & $+0.2 \%$ & $-1.79 \%^{1}$ & $-3.66 \%$ & $-4.59 \%$ \\
\hline
\end{tabular}

change rate

Note: 1. The annual EC/GDP change rates in 2003, 2004 and 2005 come from Report on the work of the government 2007 because there is no official data on EC/GDP until 2005. The annual EC/GDP change rate in 2006 is corrected into $-1.79 \%$ from original $-1.33 \%$ by NBSC in 2008 .

$$
\frac{\frac{E C}{G D P_{Y}}-\frac{E C}{G D P_{Y-1}}}{E C}
$$

2. Annual EC/GDP change rate $=\overline{\boldsymbol{G D P}}_{\boldsymbol{Y}-\mathbf{1}} \times 100 \%$. Y is the year which EC/GDP happened in and $\mathrm{Y}=\{2003,2004,2005,2006,2007,2008\}$

Source: Wen (2007) and NBSC (2006), (2007),(2008b),(2009)

Figure 1 shows the policy instruments adopted in China to date. The number of policy instruments for mitigating climate change has been rapidly increasing since 2005 and there are further policy instruments under discussion, which will be used to regulate $\mathrm{CO}_{2}$ emissions in a broader and more specific way. The administrative regulations are set up and embedded in the Chinese political system and are necessary for connecting national and provincial efforts in climate mitigation. However, the effectiveness of the administrative regulations can be better analysed on the provincial level for the years up to 2010. Technological improvement regulations have had a great increase in effect from 2007 by eliminating a large number of obsolete and lowefficiency industries and facilities. This instrument is currently making the greatest contribution to reducing energy consumption intensity through improving energy efficiency. There have been new economic instruments or adaptations of old instruments coming into force annually since 2005 but the related taxes and financial investments are at a superficial level. Different types of economic instruments are needed to cover more detailed areas and the effectiveness of all economic instruments must be improved. It is worthy of mention that some policy instruments may not take effect as soon as they are implemented. In the case of technological improvement 
regulations, for example, the focus is on long-term improvement of energy-saving technology; so many effects will not be visible at present.

Figure 1. Policy instruments adopted for climate change mitigation in China to date

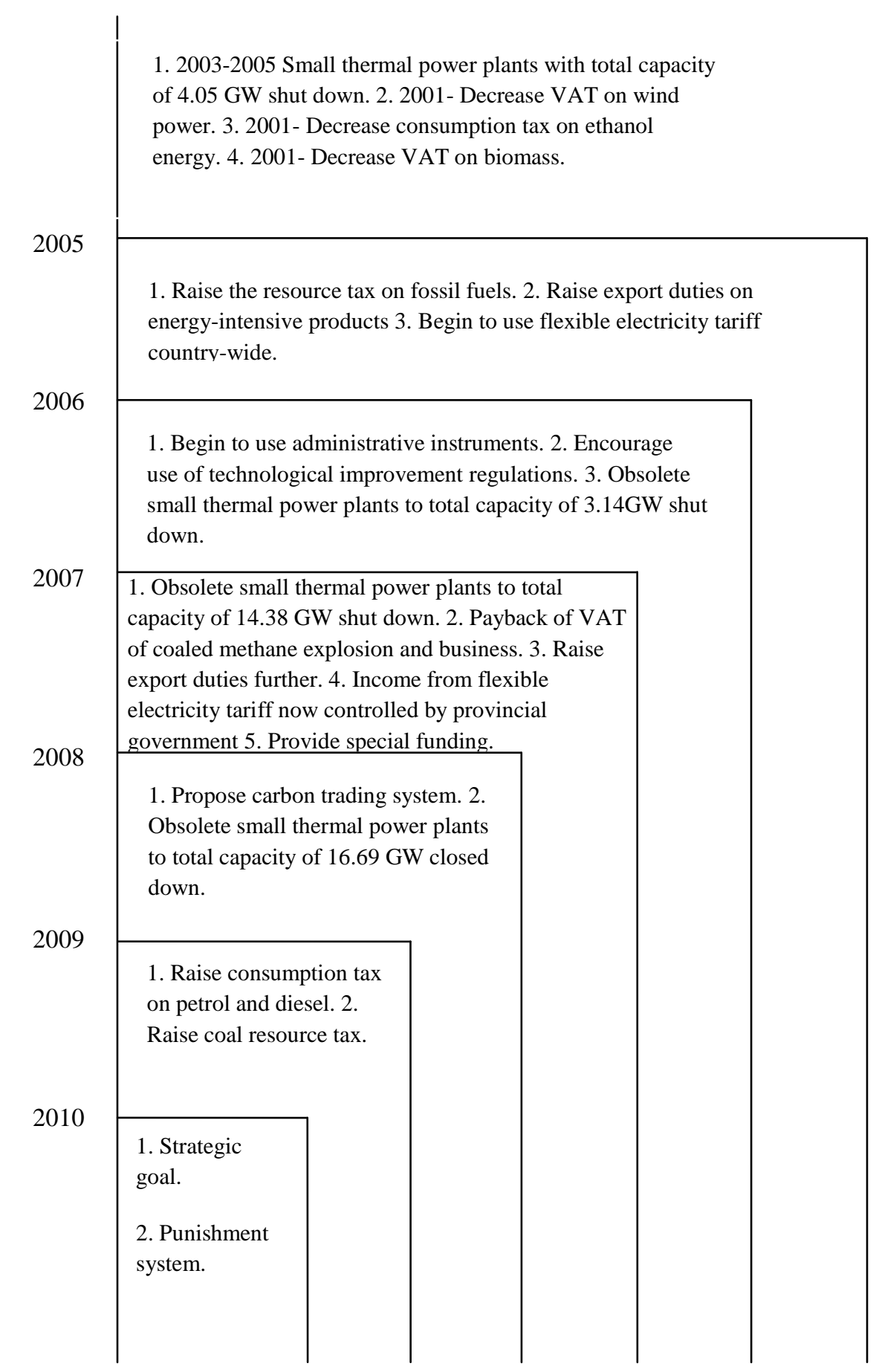

Sources: Wen (2006), (2007), (2008), (2009), CPGPRC (2007), MFPRC \& MEPPRC (2007), MEPPRC (2008) and Qian 
Although EC/GDP in China has steadily declined since 2006, in absolute terms it is still higher than the level in many developed countries (Zhu, 2004). For example, Chinese EC/GDP in 2006 was four times as big as American EC/GDP, and eight times as Japanese (He, 2007). Therefore, more ambitious approaches than policy instruments should be devised in order to mitigate climate change in a more substantial way.

\subsection{Policy instruments on provincial level}

The Chinese national strategic goal established in 2006 in response to climate change is to decrease EC/GDP by $20 \%$ by 2010 compared with the 2005 level, and specific targets have been assigned to every province. In general, the provincial targets for 2010 are $20 \%$ less than their actual EC/GDP in 2005 but the actual level depends on the practical situation in the individual province (Table IV). Seven Chinese provinces, Guangdong, Fujian, Guangxi, Yunnan, Hainan, Qinghai and Tibet, are being required to reduce EC/GDP to a degree less than $20 \%$, while four provinces, Shandong, Inner Mongolia, Shanxi and Jilin, need to decrease EC/GDP by more than $20 \%$. Provinces are allowed to address their assignments by all the legitimate means at their disposal. However, Beijing, Tianjin and Fujian were the only three provinces that reached their annual targets in 2006. This situation improved in 2007, when 10 provinces achieved their annual targets, while the remaining provinces also came much closer to their annual targets. In the following, we look at the Shandong and Beijing provinces and discuss the policy instruments adopted by their provincial governments.

4.2.1 Policy instruments in Shandong

Energy consumption in Shandong province is the highest in China (NBSC, 2008a). Economic growth in Shandong is dominated by heavy industry, which contributed $66 \%$ of the total industrial output in 2007. At the same time, $99 \%$ of electricity consumed came from coal power plants (Jiang, 2009). As Figure 2 shows, actual EC/GDP and annual EC/GDP targets in Shandong province exhibited a similar declining trend from 2006 to 2008. Although the annual targets were not fully reached, the actual EC/GDP in these years was very close to the targets.

Figure 2. Actual EC/GDP in Shandong Province 2005-2008 and annual targets 2006-2010

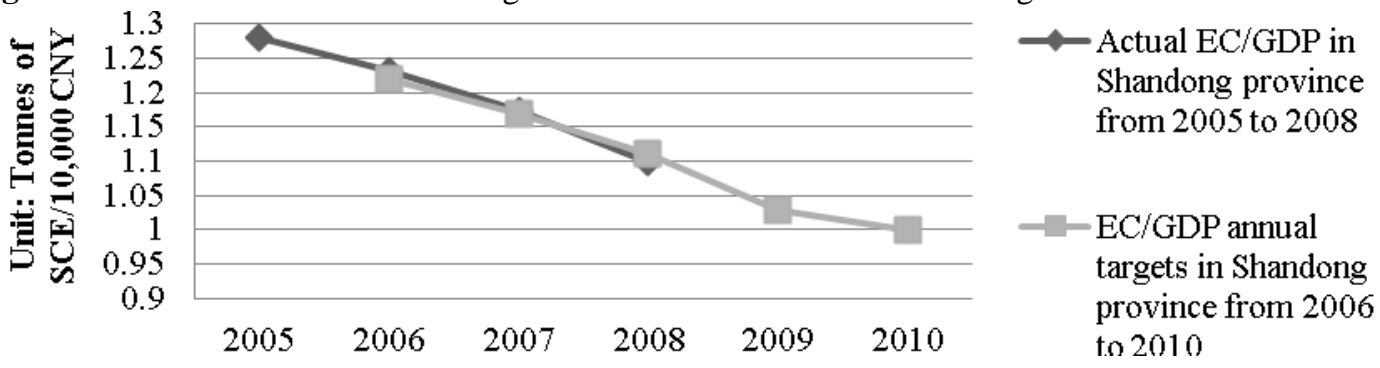

Sources: NBSC (2006, 2007, 2008b, 2009) and MEPPRC (2008)

The policy instruments used in Shandong province include administrative regulations, technological improvement regulations and economic instruments. According to the national target for 2010, Shandong province needs to reduce its EC/GDP by $22 \%$ compared with the 2005 level. In order to achieve this, Shandong province is developing provincial annual targets and dividing these targets between the various cities in the province. The cities then need to reach the targets by all legitimate means. Technological improvement regulations have also been widely used in Shandong province since 2007, e.g. in shutting down units which do not meet the sector 
baseline and replacing obsolete facilities. The provincial government evaluated the energy efficiency of 476 project applications, of which 20 projects were refused. Small thermal power plants with a total capacity of $1.717 \mathrm{GW}$ that did not meet the baseline were shut down. In addition, a large number of obsolete facilities were eliminated in the iron and steel industry, with $2,480,000$ tonnes of iron production capacity and 3,710,000 tonnes of steel production capacity being replaced (Jiang, 2009). In addition to the tax regulations imposed by the national government, Shandong province has also adopted other economic instruments. An extra tariff has to be paid for excessive energy consumption and basic caps have been set for various industrial sectors. If the amount of energy consumption is under the cap, the industry just needs to pay the normal tariff. If the amount consumed exceeds the cap, the excess is charged at a progressive tariff rate of double the normal price for less than $10 \%$ excess consumption, three times the normal price for 10\%-20\% excess, four times the normal price for 20\%-30\% excess and so forth. In order to encourage the use of renewable resources, the provincial government provides subsidies for using renewable resource in energy production. In addition, the provincial government provides special funding to encourage wind power plants and to reward industries that have saved a significant amount of energy.

\subsubsection{Policy instruments in Beijing}

The EC/GDP for Beijing in 2005 was 0.8 tonnes of SCE, which was lower than the national average (1.226 tonnes of SCE). More than $80 \%$ industrial outputs came from the tertiary industry in Beijing. Nevertheless, more than 50\% energy consumption also comes from coal energy (BMBS, 2007). As Figure 3 shows, actual EC/GDP in Beijing declined in the period 2005-2008 and its annual targets were reached in 2006, 2007 and 2008.

In order to achieve the final assignment in 2010 (0.64 tonnes of SCE), the Beijing government not only followed the national administrative regulations and set up annual targets to assist in achievement of the final assignment, but also developed its own instruments. It is trying to encourage the application of 17 typical forms of energy-saving technology. In addition, it set up an evaluation system for clean products and building projects. In 2007/08, the Beijing government reduced taxes on energy-saving and emission mitigation projects by more than 2 billion CNY and provided more than 10 billion CNY of funding to encourage the development of new projects (Guo, 2009).

Figure 3. Actual EC/GDP in Beijing 2005-2008 and annual targets 2006-2010

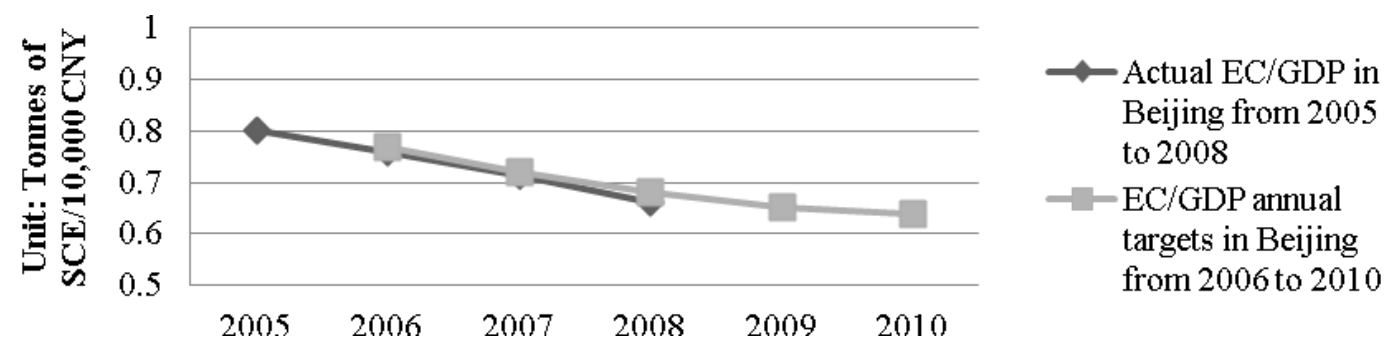

Sources: NBSC (2006, 2007, 2008b, 2009) and MEPPRC (2008)

The different provinces in China have to achieve specific EC/GDP reductions by 2010. Therefore, they are not only following the national policy instruments but have also developed quite a few new instruments to assist in achieving these reductions. Heavy industry accounts for a large proportion of Shandong's economy and coal is the main fuels used to generate power. The provincial government of Shandong opted for regulations and a few economic instruments. In 
contrast, economic instruments have been more deeply adopted in Beijing and the amount of funding and tax exemption, which aims to encourage energy-saving and emission mitigation projects, is much larger than in Shandong. Although Beijing has achieved its annual targets since 2006 and Shandong province has not, the actual EC/GDP was close to the annual targets both in Beijing and Shandong. Thus, the final assignments in 2010, which are reducing EC/GDP by $20 \%$ and $22 \%$, will be most likely achieved in Beijing and Shandong province through using different policy instruments mix.

\section{Results and Discussion}

On the basis of our analysis, we found the following important results.

(1) The decline in EC/GDP can indirectly reflect the Chinese contribution to mitigation of $\mathrm{CO}_{2}$ emissions since fossil fuels dominate Chinese energy consumption. From 2006 to 2008, EC/GDP has shown a clear declining trend on both national and provincial level, which is similar to the trend for annual targets. This means that the policy instruments, in a general sense, are very important to mitigate climate change as regard reducing EC/GDP. Nevertheless, more ambitious approaches than policy instruments should be devised in order to mitigate climate change in a more substantial way.

(2) The number of policy instruments has been rapidly increasing since 2005 and further instruments will be used to reduce $\mathrm{CO}_{2}$ emissions. Administrative regulations are embedded in the Chinese political system and are necessary for connecting national and provincial climate mitigation efforts. The effects of technological improvement regulations improved rapidly after 2007 and they currently make the greatest contribution to improving energy efficiency and reducing EC/GDP. A number of new or revised economic instruments have been coming into force annually since 2005, but these instruments still need further development.

(3) The different provinces are not only following the national policy instruments but have also developed quite a few new instruments to assist in achieving these reductions. We found similar declining trends in actual EC/GDP in our analysis of policy instruments adopted in Shandong province and Beijing. Their final targets in 2010 will be most likely achieved through using different policy instruments mix.

However, there are three major concerns regarding Chinese policy instruments in reducing EC/GDP.

First, there are some other factors simultaneously affecting EC/GDP, e.g. the structure of industry, energy market, and technology innovation. Policy instruments can be used to adjust these factors, which in turn will impact on Chinese EC/GDP. However, this paper does not go that far to determine the exact extent, to which one factor may affect the EC/GDP. A possible way to solve this would be to integrate these factors into a general equilibrium model and to simulate the general system in various assumed situations.

Second, the data used in this paper were mainly derived from annual Chinese statistical yearbooks, government reports and announcements, since these official sources were the only way for the authors to collect the broad information of policies. However, some data are lacking, e.g. the Chinese actual EC/GDP values in 2009 and the data on Tibet are not available. In addition, there are some inaccuracies contained in the existing data, e.g. the exact numbers of actual EC/GDP values in Fujian and Heilongjiang province in 2008 are described as "have achieved the goals which were assigned by the government" and thus the values of their targets are taken as their actual EC/GDP. 
Third, if the composition of Chinese energy consumption changes significantly, EC/GDP can not reflect the Chinese contribution to mitigation of $\mathrm{CO}_{2}$ emissions. A new indicator will be used to measure the efforts in mitigating climate change in China. On November 2009, Chinese government announced a new national strategic goal of $\mathrm{CO}_{2}$ mitigation, which is to reduce $\mathrm{CO}_{2}$ emission per unit GDP $\left(\mathrm{CO}_{2} / \mathrm{GDP}\right)$ by $40-45 \%$ by 2020 compared with the 2005 level (Yang, 2009). The indicator of $\mathrm{CO}_{2} / \mathrm{GDP}$ will be adopted by Chinese government in future, replacing EC/GDP to measure Chinese efforts in mitigating climate change. However, these two indicators are very close to each other given that the structure of Chinese energy mix will not be significantly adjusted in a short term. Thus, the three categories of policy instruments will still be adopted in general to reach the goal.

\section{Conclusions}

Chinese government adopts three categories of policy instruments, namely administrative regulations, technological improvement regulations and economic instruments. These policy instruments have been very important for mitigating climate change. While technological improvement regulations make the greatest contribution, the administrative regulations and economic instruments also play indispensible roles in the current policy system. The different provinces develop the policy instrument mix that is especially suitable for its own situation in order to achieve the EC/GDP targets and climate change mitigation. In addition, further research efforts are needed in order to identify the exact effectiveness of categories of policy instruments and to determine the effects of other factors.

\section{References}

BMBS (2007), Beijing Statistical Yearbook 2007, Beijing Municipal Bureau of Statistics and NBS Survey Office in Beijing, Beijing, China.

CNDRC (2007a), "China's National Climate Change Programme", Government Document, Chinese National Development and Reform Commission, Beijing, China (in Chinese).

CNDRC (2007b), "The notice of China speeds shut down of small thermal power generating units", Government Document, Chinese National Development and Reform Commission, Beijing, China (in Chinese).

CNDRC (2008), "China shut down small thermal power plants with the installed capacity totaling $25.87 \mathrm{GW}$ from 2006 to date", available at: http://nyj.ndrc.gov.cn/sdyx/t20080714_224054.htm (accessed 11 March, 2009) (in Chinese).

CCPGPRC (2006), "Outline of China's energy saving technology policies", Government Document, The Central People's Government of the People's Republic of China, Beijing, China, (in Chinese).

CPGPRC (2007), "Energy-saving emission reduction programme ", Government Document, The Central People's Government of the People's Republic of China, Beijing, China, (in Chinese).

GUO, J. (2009), Report on the work of the government in Beijing province 2009, The People's Government of Beijing Municipality, Beijing, China (in Chinese).

HE, Z. (2007), "Could the EC/GDP reflect our real situation?", available at: http://www.china.com.cn/review/txt/2007-07/13/content 8519845.htm (accessed 11 March, 2009) (in Chinese).

IPCC (2007), Climate Change 2007 Synthesis Report, Intergovernmental Panel on Climate Change, Geneva, Switzerland.

JIANG, D. (2009), Report on the work of the government in Shandong province 2009, The People's Government of Shandong Province, Jinan, China (in Chinese).

MEPPRC (2008), China national environmental protection plan in the eleventh five-years (2006-2010), Ministry of Environmental Protection of the People's Republic of China, Beijing, China.

MFPRC (2008), "The notice of the implementation of the refined oil price and tax reform by the State Council", Government Document, Ministry of Finance People's Republic of China and Ministry of Environmental Protection of the People's Republic of China, Beijing, China (in Chinese).

MFPRC and MEPPRC (2007), Reduction of major pollutants, the central financial management of special funds Interim Measures, Ministry of Finance People's Republic of China and Ministry of Environmental Protection of the People's Republic of China, Beijing, China (in Chinese). 
NBSC (2006), "Communiqué on Energy Consumption per Unit of GDP by Regions in 2005", available at: http://www.stats.gov.cn/tjgb/qttjgb/qgqttjgb/t20060630_402334002.htm (accessed 9 March, 2009).

NBSC (2007), "Communiqué on Energy Consumption per Unit of GDP by Regions in 2006", available at: http://www.stats.gov.cn/was40/gitji_en_detail.jsp?channelid=4920\&record=20 (accessed 9 March, 2009).

NBSC (2008a), China Statistical Yearbook 2008, China Statistical Press, Beijing, China.

NBSC (2008b), "Communiqué on Energy Consumption per Unit of GDP by Regions in 2007", available at: http://www.stats.gov.cn/english/newsandcomingevents/t20080715 402492159.htm (accessed 9 March, 2009).

NBSC (2009), "Communiqué on Energy Consumption per Unit of GDP by Regions in 2008", available at: http://www.stats.gov.cn/english/newsandcomingevents/t20090701_402568848.htm (accessed 9 January, 2010).

QIAN, Y. (2008), "Model way to cut emissions", available at: http://english.peopledaily.com.cn/90001/6529025.html (accessed 10 March, 2009).

SEPAC (2007), Annual statistic report on environment in China 2006, State environmental protection administration of China, Beijing, China (in Chinese).

WEN, J. (2006), Report on the work of the government 2006, The Central People's Government of the People's Republic of China, Beijing, China (in Chinese).

WEN, J. (2007), Report on the work of the government 2007, The Central People's Government of the People's Republic of China, Beijing, China (in Chinese).

WEN, J. (2008), Report on the work of the government 2008, The Central People's Government of the People's Republic of China, Beijing, China (in Chinese).

WEN, J. (2009), Report on the work of the government 2009, The Central People's Government of the People's Republic of China, Beijing, China (in Chinese).

YANG, H. (2009), "China announced a national strategic goal of $\mathrm{CO}_{2}$ mitigation", available at: http://news.xinhuanet.com/environment/2009-11/27/content 12547116.htm (accessed 20 December, 2009) (in Chinese).

ZHU, Z. (2004), International Statistical Yearbook 2003, Beijing: China Statistical Press, Beijing, China.

\section{About the authors}

Bo Xu, as the corresponding author, can be contacted at: boxu@kth.se. She is a PhD student in the department of Industrial Ecology, Royal Institute of Technology, Sweden. Her researches focus on the areas of policy instruments for climate change and energy saving. Her research interests also include the low carbon development and energy demand in China.

Qie Sun is a PhD student at the Department of Industrial Ecology, Royal Institute of Technology, Sweden. His research focuses on the management and assessment of climate change mitigation projects, especially as regard the clean development mechanism and Chinese energy and mitigation policies. His research interests also include environmental economics, sustainable urban planning and decision-making techniques.

Ronald Wennersten is the professor and the head of the Department of Industrial Ecology, Royal Institute of Technology, Sweden, the head of the Joint Research Centre for Industrial Ecology, Shandong University, China, and a guest professor at the Shandong University and the South East University, China. He has published over 100 books and articles in international journals and conferences. He is an active member of various international scientific organisations and serves as an editorial board member of various prestigious international journals.

Nils Brandt is an associate professor of the Department of Industrial Ecology, Royal Institute of Technology, Sweden. He has published more than 70 books and articles in international journals and conferences. He has supervised/co- supervised many $\mathrm{PhD}$ and master students. His research area includes sustainable urban planning, industrial ecology, climate change actions and strategies, environmental system analysis and ecological engineering. 